\title{
Brexpiprazole for the maintenance treatment of adults with schizophrenia: an evidence-based review and place in therapy
}

This article was published in the following Dove Medical Press journal: Neuropsychiatric Disease and Treatment

\author{
Kristen Ward' \\ Leslie Citrome ${ }^{2}$ \\ 'Department of Clinical Pharmacy, \\ University of Michigan College \\ of Pharmacy, Ann Arbor, MI, USA; \\ ${ }^{2}$ Department of Psychiatry and \\ Behavioral Science, New York Medical \\ College, Valhalla, NY, USA
}

\begin{abstract}
The purpose of this review is to describe the available data for brexpiprazole in the maintenance treatment of schizophrenia. This objective was completed by searching the databases PubMed, Embase, and ClinicalTrials.gov to identify relevant study results presented as papers or abstracts. In summary, brexpiprazole is a new agent in the $\mathrm{D}_{2}$ partial agonist class that has a unique receptor-binding profile, based in part on high affinity for serotonin $5 \mathrm{HT}_{1 \mathrm{~A}}$ and $5 \mathrm{HT}_{2 \mathrm{~A}}$ receptors, paired with lower intrinsic activity at dopamine $\mathrm{D}_{2}$ receptors. The average dose used in efficacy and safety studies for the maintenance treatment of schizophrenia ranged from 3.0 and $3.1 \mathrm{mg}$ in the open-label safety studies to $3.6 \mathrm{mg}$ in the double-blind randomized relapse-prevention study. Highlights from the 52-week double-blind placebo-controlled relapse-prevention trial evidenced rates of relapse in the brexpiprazole group of $13.5 \% \mathrm{vs} 38.5 \%$ in the placebo group (number needed to treat $4,95 \%$ CI $3-8 ; P<0.0001$ ). Safety data indicate that brexpiprazole is tolerated well, with rates of discontinuation due to treatment-emergent adverse events that ranged from $5.2 \%$ of those taking brexpiprazole in the double-blind maintenance phase of the relapse-prevention trial to $15.3 \%$ in a 52-week open-label safety study. In the available trials, there were relatively low rates of akathisia, and the degree of weight gain was similar to that seen in studies with aripiprazole for the treatment of schizophrenia. Positive and Negative Syndrome Scale scores also remained relatively stable in the open-label safety studies. Available data indicate that brexpiprazole is an effective agent for the maintenance treatment of schizophrenia that is overall well tolerated. Keywords: akathisia, weight gain, second-generation antipsychotics, atypical antipsychotics, relapse prevention
\end{abstract}

\section{Plain-language summary}

It can be difficult for patients with schizophrenia to find antipsychotic medications that work well for them and that cause few side effects. Brexpiprazole is a newer antipsychotic that has been shown to be a safe and effective long-term medication for the treatment of schizophrenia. Based on side-effect data from research studies, brexpiprazole may be particularly beneficial for patients who have struggled with restlessness or akathisia during past medication trials or those who are looking for an alternative medication that is not highly sedating. Since most of the research with brexpiprazole has been in adults aged 18-65 years, more work is needed to determine how safe and effective brexpiprazole is for younger and older patients.

\section{Introduction}

Brexpiprazole is among the newest dopamine $\mathrm{D}_{2}$ partial agonist antipsychotics in a class that includes aripiprazole and cariprazine, and has a unique receptor-binding profile. ${ }^{1,2}$ The US Food and Drug Administration (FDA) approved brexpiprazole in 2015 for the treatment of schizophrenia and as an adjunct for the treatment of depression,
Correspondence: Leslie Citrome Department of Psychiatry and Behavioral Science, New York Medical College, 40 Sunshine Cottage Rd, Valhalla, NY 10595, USA

Tel +l $845362208 I$

Fax +l 8453628745

Email citrome@cnsconsultant.com 
following the completion of several acute efficacy trials. ${ }^{3-7}$ Recently, clinical trial results have reported on efficacy and safety outcomes from long-term (52-week) investigations of brexpiprazole for the treatment of schizophrenia in adults. ${ }^{8-10}$ Therefore, the objective of this review is to describe brexpiprazole pharmacology and evidence for its tolerability, safety, and efficacy as a maintenance agent for the treatment of schizophrenia in adults, concluding with a discussion of the potential role of brexpiprazole in the overall management of schizophrenia.

\section{Methods}

PubMed, Embase, and ClinicalTrials.gov were searched for study results pertaining to the use of brexpiprazole for the maintenance treatment of schizophrenia. The first search was conducted on September 26, 2018. The following terms were used: PubMed (schizophrenia[mh] OR schizophrenia[tiab] OR dopamine $\mathrm{D}_{2}$-receptor partial agonist) AND brexpiprazole AND (safety[tiab] OR efficacy[tiab] OR therapeutic use OR adverse effects[subheading] OR “adverse effects"[tiab]); Embase ("schizophrenia"/exp OR schizophrenia:ab,ti) AND ("brexpiprazole"/exp OR brexpiprazole:ab,ti) AND (["safety"/exp OR “efficacy"/exp OR “therapy”/exp OR "adverse event"/exp] OR [safety:ab,ti OR efficacy:ab,ti OR “therapeutic use":ab,ti OR “adverse effects":ab,ti]). This strategy identified 60 entries in PubMed and 152 in EMBASE. Between September 26 and November 4, 2018, two additional entries were identified in PubMed and one in Embase. The ClinicalTrials.gov search of "brexpiprazole" or "OPC-34712" AND "schizophrenia" resulted in the identification of 35 clinical trials, 4 of which were still recruiting. Among the search results were reports of three 52-week clinical trials and select secondary analyses, which are discussed in more detail herein.

\section{Pharmacodynamics}

Brexpiprazole is an antagonist of the serotonin $5 \mathrm{HT}_{2 \mathrm{~A}}$, $5 \mathrm{HT}_{2 \mathrm{~B}}, 5 \mathrm{HT}_{7}$, and adrenergic $\alpha_{1 \mathrm{~B}}$ and $\alpha_{2 \mathrm{C}}$ receptors, and a partial agonist of dopamine $\mathrm{D}_{2}, \mathrm{D}_{3}$, and serotonin $5 \mathrm{HT}_{1 \mathrm{~A}}$ receptors. ${ }^{11}$ In vitro receptor-binding studies indicate a high affinity $\left(\mathrm{K}_{\mathrm{i}}<1 \mathrm{nM}\right)$ for the $\mathrm{D}_{2}, 5 \mathrm{HT}_{1 \mathrm{~A}}, 5 \mathrm{HT}_{2 \mathrm{~A}}, \alpha_{1 \mathrm{~B}}$, and $\alpha_{2 \mathrm{C}}$ receptors. Brexpiprazole also exhibits nanomolar affinity for $\mathrm{D}_{3}\left(\mathrm{~K}_{\mathrm{i}} 1.1 \mathrm{nM}\right), 5 \mathrm{HT}_{2 \mathrm{~B}}\left(\mathrm{~K}_{\mathrm{i}} 1.9 \mathrm{nM}\right)$, and $5 \mathrm{HT}_{7}$ $\left(\mathrm{K}_{\mathrm{i}} 3.7 \mathrm{nM}\right)$ receptors, as well as moderate affinity for histamine $\mathrm{H}_{1}$ receptors $\left(\mathrm{K}_{\mathrm{i}} 19 \mathrm{nM}\right)$ and very low affinity for muscarinic $M_{1}$ receptors $\left(K_{i}>1,000 \mathrm{nM}\right) .{ }^{11}$ Ideally, the high affinity for the $5 \mathrm{HT}_{1 \mathrm{~A}}$ and $5 \mathrm{HT}_{2 \mathrm{~A}}$ receptors, paired with lower intrinsic activity at $\mathrm{D}_{2}$, would translate to clinically favorable antipsychotic efficacy, while avoiding adverse events (AEs) associated with potent agonism or antagonism of the $\mathrm{D}_{2}$ receptor. ${ }^{11}$ Similarly, moderate to low affinity for the $H_{1}$ and $M_{1}$ receptors is expected to correlate with low propensity for sedation, weight gain, and anticholinergic side effects like xerostomia and constipation. ${ }^{12}$

\section{Pharmacokinetics}

Brexpiprazole pharmacokinetic data are summarized in the FDA-approved product label (see Table 1). ${ }^{3}$ Highlights of brexpiprazole pharmacokinetic studies include the observation that absorption does not appear to be significantly impacted by food or change in $\mathrm{pH}$, as noted by minimal change in absorption variables in fasting and fed states, as well as in the presence of the proton-pump inhibitor omeprazole. With respect to distribution, brexpiprazole is highly protein-bound $(>99 \%)$, although in vitro data suggest that it will not be displaced by warfarin, diazepam, or digoxin, and protein binding does not appear to be impacted by renal or hepatic dysfunction. Brexpiprazole relies primarily on the CYP450 isoenzymes CYP3A4 and CYP2D6 for metabolism and formation of inactive metabolites. Strong inhibitors of CYP3A4 and CYP2D6 increase exposure, as measured by an approximate twofold increase in area under the curve (AUC). When a strong CYP2D6 inhibitor is used in combination with a strong CYP3A4 inhibitor (or a strong CYP3A4 inhibitor is used by a poor CYP2D6 metabolizer), brexpiprazole AUC increases approximately fivefold. The package label suggests dosage adjustment for patients on moderate-strong CYP3A4 or CYP2D6 inhibitors, or for known poor-CYP2D6-metabolizer status, but does not require pharmacogenetic testing prior to use. Finally, brexpiprazole is excreted in the urine and feces, mostly as metabolites. Studies in patients with renal and hepatic impairment have noted increases in AUC, particularly in those with severe renal dysfunction and moderate hepatic impairment, resulting in recommended dose decreases for patients with moderate-severe renal or hepatic impairment. Dosage adjustments relevant to metabolism and excretion are listed in Table 1.

\section{Overview of long-term clinical trials of brexpiprazole for treatment of schizophrenia}

The literature search identified published results pertaining to three phase III 52-week clinical trials assessing the safety and efficacy of brexpiprazole for the management of schizophrenia. ${ }^{8-10}$ Two were open-label, flexible-dose safety studies ${ }^{9,10}$ that enrolled patients who had completed short-term efficacy trials with brexpiprazole or patients new to brexpiprazole therapy, and the third was a randomized, 
Table I Pharmacokinetic (PK) parameters of brexpiprazole and practical implications ${ }^{3}$

\begin{tabular}{|c|c|c|}
\hline & PK study results & Implications \\
\hline Absorption & $\begin{array}{l}\text { - Oral bioavailability } 95 \% \\
\text { - Absorption not significantly impacted by food or } \\
\text { omeprazole }\end{array}$ & $\begin{array}{l}\text { - Dosing can be with or without food } \\
\text { - Unlikely that changes in } \mathrm{pH} \text { will significantly impact absorption }\end{array}$ \\
\hline Distribution & $\begin{array}{l}\text { - Volume of distribution: } 1.56 \pm 0.42 \mathrm{~L} / \mathrm{kg} \\
\text { - }>99 \% \text { protein bound in plasma } \\
\text { o not displaced by warfarin digoxin or diazepam } \\
\text { not impacted by renal or hepatic dysfunction }\end{array}$ & $\begin{array}{l}\text { - High volume of distribution: medication enters extravascular tissue } \\
\text { Despite high protein binding, drug-drug interactions with other } \\
\text { highly protein-bound medications (warfarin, digoxin, diazepam), } \\
\text { and renal or hepatic dysfunction are not likely to cause clinically } \\
\text { significant changes in protein binding }\end{array}$ \\
\hline Metabolism & $\begin{array}{l}\text { - Primarily metabolized by CYP3A4 and CYP2D6 } \\
\text { - Not predicted to significantly impact common } \\
\text { metabolizing enzymes or transporters (CYP2D6, } \\
\text { CYP3A4, CYP2B6, BCRP, and P-gP) } \\
\text { - Major metabolite is not considered active }\end{array}$ & $\begin{array}{l}\text { Half dose in presence of: } \\
\text { - known CYP2D6 poor metabolizers } \\
\text { - strong CYP2D6 inhibitors OR CYP3A4 inhibitors } \\
\text { Quarter dose in presence of: } \\
\text { - strong/moderate CYP2D6 inhibitors (or in persons who are } \\
\text { CYP2D6 poor metabolizers) in combination with strong/moderate } \\
\text { CYP3A4 inhibitors } \\
\text { Double dose in presence of: } \\
\text { - strong CYP3A4 inducers } \\
\text { - increase brexpiprazole dose over I-2 weeks } \\
\text { Brexpiprazole is unlikely to impact the serum concentration of } \\
\text { other medications }\end{array}$ \\
\hline Excretion & $\begin{array}{l}\text { - } 25 \% \text { recovered in urine, } 1 \% \text { unchanged } \\
\text { - } \sim 6 \% \text { recovered in feces, } 14 \% \text { unchanged } \\
\text { - } t_{1 / 2}: 91 \text { hours }\end{array}$ & $\begin{array}{l}\text { - Moderate or worse renal impairment }(\mathrm{CrCl}<60 \mathrm{~mL} / \text { minute) and } \\
\text { moderate-severe hepatic impairment (Child-Pugh score } \geq 7) \text { : } \\
\text { maximum recommended dose is } 3 \mathrm{mg} \text { daily for schizophrenia } \\
\text { - Long } t_{1 / 2} \text { allows for once-daily dosing }\end{array}$ \\
\hline
\end{tabular}

Abbreviations: $\mathrm{CrCl}$, creatinine clearance; $t_{1 / 2}$, elimination half-life.

double-blind, placebo-controlled, relapse-prevention trial. ${ }^{8}$ The relapse-prevention trial ${ }^{8}$ was terminated early, and the open-label safety study conducted by Forbes et $\mathrm{al}^{10}$ was amended to decrease the trial length, as the investigative teams in both studies noted early collection of adequate safety and efficacy data. These trials are summarized in Table 2 and discussed in more detail herein.

\section{Relapse-prevention trial}

Fleischhacker et al completed an international, double-blind, randomized, placebo-controlled study with the goal of determining the efficacy of brexpiprazole as a maintenance agent for the treatment of schizophrenia. ${ }^{8}$ They enrolled patients who were 18-65 years old and had a diagnosis of schizophrenia for at least the last 3 years per Diagnostic and Statistical Manual of Mental Disorders (DSM)-IVTR criteria, ${ }^{13}$ and at the time of enrollment, they had to be experiencing an acute schizophrenia relapse and have a history of relapse or worsening symptoms in the absence of an antipsychotic. The criterion for acute relapse was defined as a Positive and Negative Syndrome Scale (PANSS) score $>80$. Additional requirements related to medication use were demonstrated response to an antipsychotic in the past year (other than clozapine), and no treatment with an antidepressant for depression in the past 30 days. Finally, anyone with an axis I diagnosis other than schizophrenia, those identified as a high risk for suicide or violent behavior, or those who had a history of substance abuse or dependence in the past 180 days were also excluded.

Several study phases were designed to account for the time necessary to cross-titrate from the current antipsychotic to brexpiprazole, if necessary (open-label conversion phase), followed by a single-blind, brexpiprazole-stabilization phase, then finally a maintenance phase for up to an additional 52 weeks. The conversion phase was completed over 1-4 weeks at the investigators' discretion, and the stabilization phase could take between 12 and 36 weeks. For a patient to be considered stabilized, they had to meet all predefined stability criteria weekly for 12 consecutive weeks and be on a stable dose of brexpiprazole (1-4 mg daily) for the last 4 weeks to continue in the trial. These criteria included an absence of suicidal or aggressive behavior, no more than moderate illness severity on the Clinical Global Impression severity (CGI-S) subscale, a total PANSS score $\leq 70$, and a score no higher than 4 for the PANSS subitems conceptual disorganization, hallucinatory behavior, unusual thought content, or suspiciousness. If all criteria were met, the participant would enter the double-blind maintenance phase and then randomized to placebo or brexpiprazole. If they did not meet stability criteria, they were excluded from the trial. 


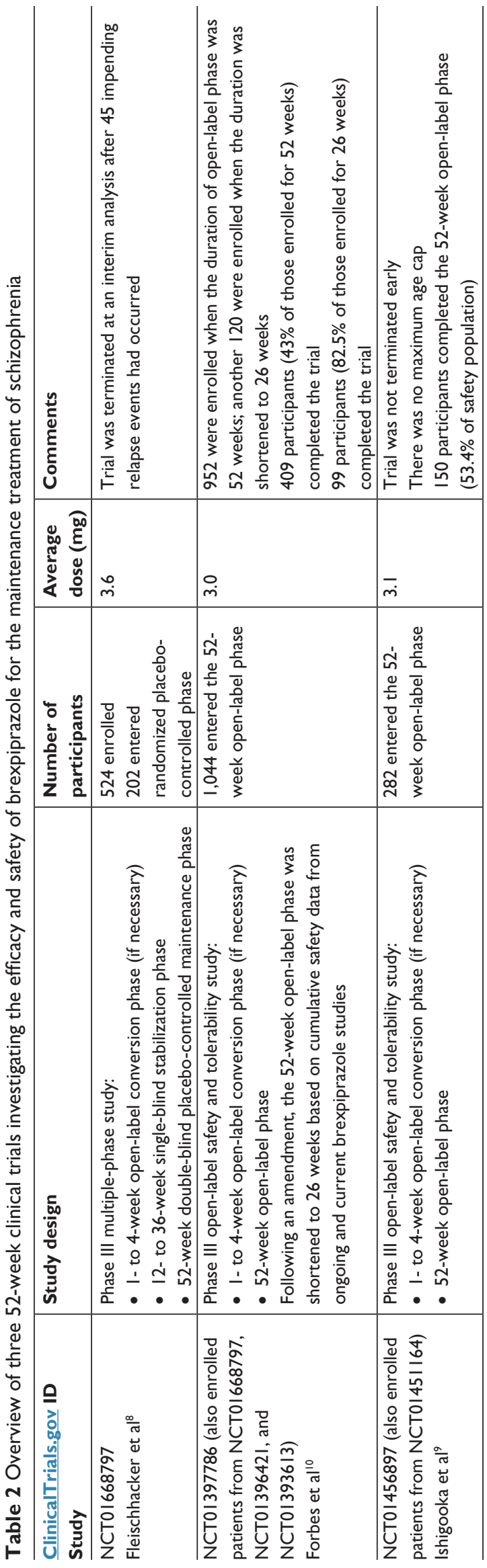

The primary efficacy analysis was time to impending relapse or exacerbation of symptoms, at which point the participant would be withdrawn from the study. Criteria that were used to judge impending relapse included meeting any of the following: 1) hospitalization due to worsening of psychosis; 2) suicidal behavior; 3) violent or aggressive behavior resulting in injury or property damage; or 4) CGI improvement scale (CGII) score of $\geq 5$ (i.e., at least minimally worse) combined with an increase on any of the following PANSS items: conceptual disorganization, suspiciousness, hallucinatory behavior, and unusual thought content (a) to a score of $>4$ with an absolute increase of $\geq 2$ on that specific item since randomization, or (b) to a score of $>4$ with an absolute increase of $\geq 4$ on the combined 4 PANSS items since randomization. Safety was measured with reporting of treatment-emergent AEs (TEAEs), changes in laboratory tests that included a lipid panel and prolactin, anthropometric measurements, vital signs, and electrocardiography. Extrapyramidal symptoms (EPSs) were assessed using the Simpson-Angus Scale, the Barnes Akathisia Rating Scale, and the Abnormal Involuntary Movement Scale. Secondary efficacy end points included assessments of patient functioning with the Global Assessment of Functioning and Personal and Social Performance (PSP) scales, and cognition with the Cogstate computerized cognitive test battery. Suicidality was measured by the Columbia Suicide Severity Rating Scale. Visits occurred in the maintenance phase every 2 weeks for 8 weeks, then every 4 weeks until completion of the trial or discontinuation.

Time to relapse was compared between treatment and placebo groups using a two-sided log-rank test with a significance threshold of 0.05 . The study team's predetermined requirement for the number of events needed to identify brexpiprazole's efficacy as a maintenance agent adequately was 90 occurrences of impending relapse. However, the investigators also set two interim analyses to occur after 45 and 68 impending relapse events to minimize patient exposure to placebo in the event that the difference between groups was large enough to end the trial early. Participant data were analyzed separately by study phase. Those included in the efficacy analyses were any patients who had had at least one dose of study medication in a given phase and also had had at least one efficacy evaluation after baseline in the given phase. Safety analyses included anyone who had had at least one dose of medication in the given phase.

The results of the first interim analysis were positive, and the study was terminated. At the time of study termination, of 524 enrolled participants, 202 had entered the maintenance phase and 97 had been randomized to brexpiprazole, with the 
remaining 105 randomized to placebo. Baseline demographic data for those entering the double-blind maintenance phase (ie, randomized phase) include an average age (SD) of 38.8 (10.7) years old in the brexpiprazole group and 41.6 (10.6) in the placebo group, an average body-mass index (BMI) of 28.2 (6.7) in the brexpiprazole group and 29.1 (6.9) in the placebo group, roughly $40 \%$ female, and approximately $63 \%$ white. Mean daily dose at the last visit in the maintenance phase was $3.6 \mathrm{mg}$, and approximately $51.5 \%$ of participants were exposed to brexpiprazole through week 24 , but only 23 received brexpiprazole through week 52 . Unsurprisingly, the majority of patients who did not complete the trial were discontinued by the sponsor following early termination of the study after the first interim analysis ( 87 of 202 patients in the maintenance phase). Rates of discontinuation because of TEAEs are provided in Table 3.

The interim analysis included 45 relapse events in a total of 167 patients, and the final analysis included 53 relapse events in 200 total patients. The following results were identified by the investigators using the final analysis data set. The primary efficacy analysis, time to impending relapse, was significant, as noted by an HR of 0.292 (95\% CI $0.156-0.548, P<0.0001)$ in favor of brexpiprazole over placebo. Among those taking brexpiprazole, $13.5 \%$ vs $38.5 \%$ of the placebo group met criteria for impending relapse $\left(\chi^{2}\right.$ test, number needed to treat $4,95 \%$ CI $3-8 ; P<0.001) .{ }^{14}$ Furthermore, at the participant's last visit in the double-blind phase, $79.2 \%$ (76 of 96) of those taking brexpiprazole still met stability criteria vs $56.7 \%$ (59 of 104) in the placebo group ( $\chi^{2}$ test, $P=0.0007$ ). Additional significant secondaryefficacy end-point measures included greater least-squares mean increase in PANSS score for the placebo group (increase of 11.20 points in the placebo group vs 3.25 points in the brexpiprazole group, last observation carried forward [LOCF]; ANCOVA $P=0.0007$ ) and better scores for those on brexpiprazole vs placebo on the PSP and Global Assessment of Functioning scales (LOCF $P<0.01$ ).

With respect to TEAEs, $43.3 \%$ of patients taking brexpiprazole in the randomized phase experienced at least one TEAE (42 of 97) compared to $55.8 \%$ in the placebo group (58 of 104). TEAEs that occurred in $>5 \%$ of patients in the stabilization or maintenance phase are included in Table 3. Higher rates of clinically relevant weight gain, identified as $\geq 7 \%$, were more likely to occur in the stabilization phase $(11.3 \%)$ over the maintenance phase $(5.2 \%)$ for patients taking brexpiprazole. Patients who were switched from brexpiprazole to placebo in the maintenance phase lost an average of $2.2 \mathrm{~kg}$ by their last visit, and patients who stayed on brexpiprazole lost an average of $0.3 \mathrm{~kg}$ by their last visit. In the maintenance phase, there were no differences between the treatment and control groups with respect to EPS scores, and the only other significant differences between the placebo and treatment groups in the maintenance phase were increases in fasting triglycerides $\geq 50 \mathrm{mg} / \mathrm{dL}$ in $16.3 \%$ of the brexpiprazole group vs $7.4 \%$ of the placebo group. This translated to $7 \%$ of patients in the brexpiprazole group transitioning from normal $(<150 \mathrm{mg} / \mathrm{dL})$ to high fasting triglycerides $(200$ to $<500$ $\mathrm{mg} / \mathrm{dL}$ ) vs 0 in the placebo group.

\section{Safety trial I}

Forbes et al recently published results of a long-term trial investigating the safety of brexpiprazole over a period of up to 52 weeks in a phase III, international, open-label trial that also described secondary-efficacy outcomes. They capitalized on previous research efforts by enrolling patients from up to three prior phase III studies, including the aforementioned investigation by Fleischhacker et $\mathrm{al}^{8}$ and two 6-week acute efficacy trials, ${ }^{4,5}$ in addition to patients who had never previously participated in a brexpiprazole study. Participants from the two short-term trials could enter this study upon completion of either acute study, and participants from the relapse-prevention trial could enter after completing the study or at the time of impending relapse. For patients new to a brexpiprazole study, inclusion criteria mirrored those of the Fleischhacker et al trial. Criteria for entering the open-label safety study directly required no use of an antipsychotic in the last week, or there was a 4-week cross-titration phase that ended with the participant on brexpiprazole $2 \mathrm{mg}$ daily before entering the 52-week open-label phase. Upon entering the open-label phase, participants could have their dose adjusted in $1 \mathrm{mg}$ increments to improve tolerability or efficacy at the investigator's discretion, as long as the daily dose stayed within a range of $1-4 \mathrm{mg}$.

Visits after the 52-week extension phase began were at weeks 1, 2, 4, and 8, and then every 6 weeks. Safety measures, including EPS assessments, were the same as previously described for the relapse-prevention trial. Select secondary end-point efficacy measures included changes from baseline in the PANSS, CGI-S, CGI-I, and PSP. The PSP was measured at weeks 2, 8, 26, and 52. During the trial, the investigators amended the study to shorten the open-label phase from 52 to 26 weeks, based on safety data that were deemed adequate when considering pooled results from the acute trials and the relapse-prevention trial, in combination with available data from this investigation. 


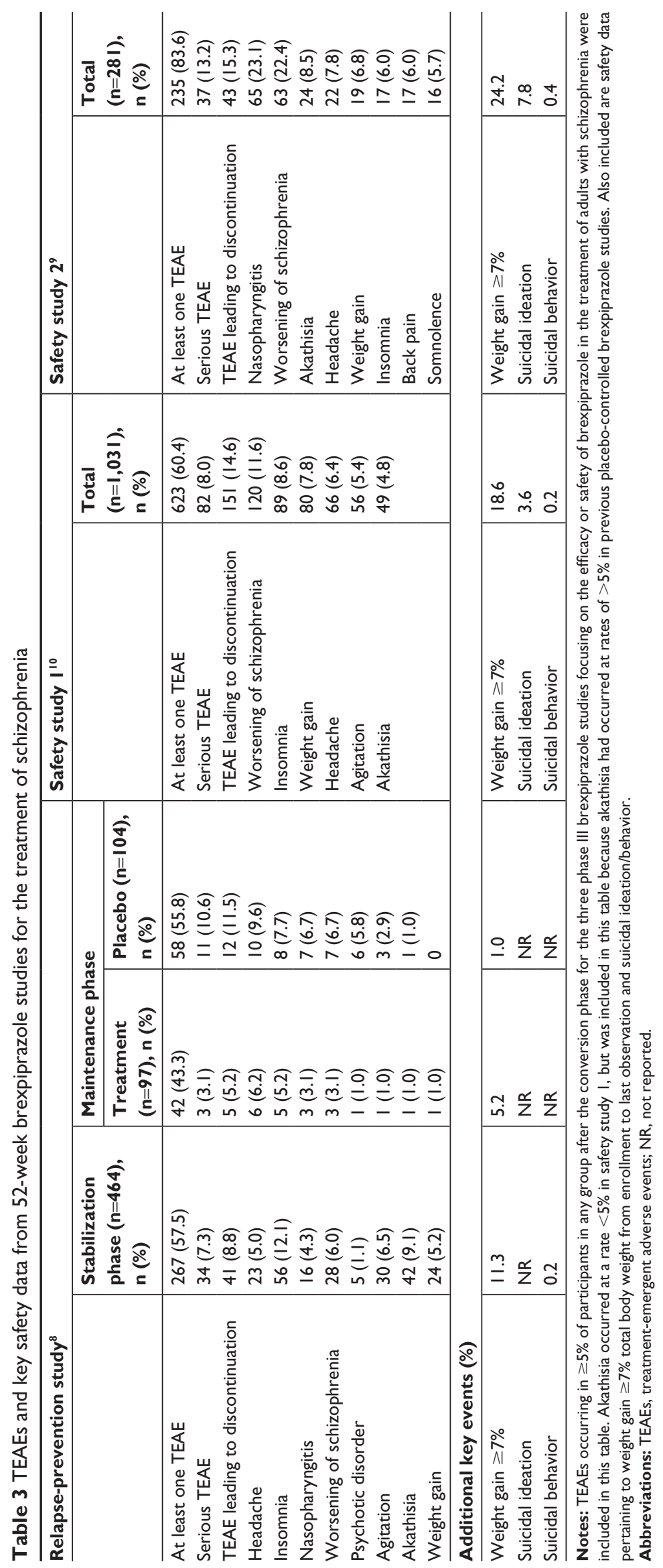


Of the 1,072 patients who were enrolled, most (952) were enrolled prior to the amendment that shortened the trial duration to 26 weeks (120 additional participants). The average age (SD) of the participants was 40.0 (11.1) years, 38.2\% were female, and the average BMI (SD) was 27.9 (6.6). The majority $(62 \%)$ of the population was white. Of the 1,072 patients, only 28 discontinued during the conversion phase, and of the remaining 1,044, most (815) had participated in one of the previous studies. However, with regard to those who were previously exposed to brexpiprazole, the number decreased to 611 (58.5\%), as the rest had received placebo in one of the previous trials. All patient data from those who had received at least one dose of brexpiprazole after the conversion phase were included in the represented in the safety results $(1,031)$, and all patients who were in the safety group and had had at least one efficacy evaluation in the open-label phase $(1,021)$ were represented in the efficacy results. Among the safety group, the average PANSS score (SD) when entering the trial was 69.5 (17.2), which is indicative of mild-moderate severity symptoms.

The number of patients completing the study ranged from $43 \%$ (409 of 952) to $82.5 \%$ (99 of 120) for those enrolled for 52 or 26 weeks, respectively. The most common reason for discontinuation was patient withdrawal of consent (177, 16.5\%), followed by withdrawal due to TEAEs (159, $14.8 \%$ ). The average daily dose at the last visit was $3 \mathrm{mg}$, and the majority of patients (60.4\%) experienced at least one TEAE. Most were described as mild-moderate, but $82(8.0 \%)$ experienced a severe TEAE. For those who discontinued due to a TEAE, the most common reason was for worsening of schizophrenia/psychotic disorder. Table 3 includes data on TEAEs. With respect to adverse metabolic events, the percentage of patients who experienced a weight increase of $\geq 7 \%$ was $18.6 \%$ and the percentage of new patients meeting metabolic syndrome criteria was $3.8 \%$, although there were no significant changes in measured labs or QT prolongation. There were also no clinically meaningful changes in EPS rating scales, although one patient developed tardive dyskinesia after 393 days' exposure to brexpiprazole that was considered moderately severe. Other potentially serious AEs included one overdose that was not associated with any lasting effects, and one woman became pregnant while taking brexpiprazole in the first trimester. She was removed from the study and later had a healthy baby. Suicidal ideation determined to be a TEAE occurred in $0.6 \%$ of patients, and hospitalization for exacerbation occurred in $10.5 \%$.

With respect to efficacy, for patients that completed the trial through week 52, the average decrease in PANSS total score was 12.2 (SD 15.0) from baseline, and improvement was seen for patients who had previously been on brexpiprazole, placebo, or did not enter from another clinical trial. CGI-S scores indicated a transition from mildly-moderately ill at baseline to mildly ill by week 52, and PSP scores also improved steadily over 52 weeks, increasing by an average of 7.7 (SD 11.0). Table 4 provides additional data on efficacy measures.

\section{Safety trial 2}

Another 52-week multisite open-label safety trial ${ }^{9}$ was conducted in Japan that enrolled adult patients from a national

Table 4 Efficacy measures from the two open-label 52-week safety studies of brexpiprazole for the treatment of schizophrenia

\begin{tabular}{|c|c|c|c|c|}
\hline & \multicolumn{2}{|l|}{ Safety study $\mathrm{I}^{10}$} & \multicolumn{2}{|l|}{ Safety study $2^{9}$} \\
\hline & $\begin{array}{l}\text { Open-label phase, } \\
\text { baseline }(n=I, 024), \\
\text { mean (SD) }\end{array}$ & $\begin{array}{l}\text { Change for } \\
\text { completers }(n=4 \mid 0) \text {, } \\
\text { mean (SD) }\end{array}$ & $\begin{array}{l}\text { Open-label phase, } \\
\text { baseline }(n=279) \text {, } \\
\text { mean (SD) }\end{array}$ & $\begin{array}{l}\text { Change for } \\
\text { completers }(n=\mid 50) \text {, } \\
\text { mean (SD) }\end{array}$ \\
\hline PANSS total score & $68.5(17.1)$ & $-12.2(15.0)$ & $72.6(22.4)$ & $-7.7(12.0)$ \\
\hline PANSS positive & $16.3(5.4)$ & $-3.6(4.8)$ & $15.7(6.0)$ & $-1.3(3.3)$ \\
\hline PANSS negative & $19.0(5.3)$ & $-2.8(4.6)$ & $20.0(6.9)$ & $-2.2(4.0)$ \\
\hline PANSS excited & $8.6(3.3)$ & $-1.5(3.2)$ & $9.5(3.8)$ & $-0.8(1.9)$ \\
\hline CGI-S & $3.5(0.9)$ & $-0.6(0.9)$ & $3.5(1.1)$ & $-0.3(0.7)$ \\
\hline \multicolumn{5}{|l|}{ PANSS Marder factor scores } \\
\hline Positive & $20.2(6.1)$ & $-4.2(5.4)$ & $19.8(7.2)$ & $-1.8(3.8)$ \\
\hline Negative & $17.6(5.4)$ & $-2.8(4.4)$ & $19.4(6.8)$ & $-2.4(4.4)$ \\
\hline Disorganized thought & $16.7(4.9)$ & $-2.9(4.0)$ & $17.5(6.2)$ & $-2.0(3.2)$ \\
\hline Uncontrolled hostility/excitement & $6.6(2.8)$ & $-I . I(2.7)$ & $7.4(3.2)$ & $-0.6(1.5)$ \\
\hline Anxiety/depression & $7.3(3.0)$ & $-1.2(2.9)$ & $8.5(3.0)$ & $-1.0(2.3)$ \\
\hline
\end{tabular}

Note: Efficacy data in this table include only those who completed the 52-week phase of brexpiprazole treatment in either safety study.

Abbreviations: CGI-S, Clinical Global Impression - Severity; PANSS, Positive and Negative Syndrome Scale. 
acute efficacy trial ${ }^{15}$ or patients new to a brexpiprazole study. Inclusion criteria, exclusion criteria, and study design were similar to the international open-label safety study described previously, although study visits were more frequent after week 8 of the maintenance phase (every 4 weeks vs every 6 weeks) and there was no age maximum. In total, 282 patients were enrolled in this trial. Of those, 184 were new to a brexpiprazole study and 98 were rolled over from the earlier acute efficacy trial. Characteristics of those who entered the open-label treatment phase include an average age (SD) of 44.4 (14.0) years, 53.9\% female, average BMI (SD) of 23.7 (4.4), and average PANSS score (SD) at baseline of 72.7 (22.3). Among the 282 enrolled, 33 were over the age of 65 years, and among this age group, 29 entered the open-label phase. In total, three of the participants aged $>65$ years discontinued due to TEAEs of insomnia, thirst, and worsening of schizophrenia symptoms. TEAEs are summarized in Table 3.

Unlike the two prior studies, this trial was not stopped early by the investigators. A total of 109 (59.2\%) new patients and $41(41.8 \%)$ rollover patients completed the study through week 52 , and 281 were included in the safety analysis. The average time of exposure (SD) was 236 (148) days and the average dose (SD) was $3.1(0.8) \mathrm{mg}$ daily. Compared to the previously discussed open-label trial, there were similar rates of discontinuation from the study due to TEAEs $(15.3 \%, \mathrm{n}=43)$. Serious TEAEs $(13.2 \%)$ were most commonly worsening of schizophrenia, which in turn was the most frequent TEAE leading to discontinuation. Akathisia occurred in an average of $8.5 \%$ of patients and was the reason for discontinuation for three patients (1.1\%). With respect to weight gain, for those who completed the study through week 52 , the average weight gain was $1.61 \mathrm{~kg}$ and weight gain $\geq 7 \%$ from baseline occurred in a total of $24.2 \%$ of patients included in the open-label safety analysis. There were no clinically relevant changes in measured labs, electrocardiography, or EPS-scale scores. Suicidal ideation occurred at a higher rate than reported in the other long-term brexpiprazole studies (7.8\%), although suicidal behavior was similar $(\mathrm{n}=1,0.4 \%)$.

Although not the primary focus of this study, openlabel efficacy data were analyzed for 279 patients. As in the previous trials, long-term brexpiprazole use resulted in relative stability in PANSS total score over the 52-week open-label phase by average change (SD) of -2.92 (13.77) on LOCF analysis. Furthermore, the range of change in component measures of the PANSS was relatively narrow, with an average difference (SD) of -1.37 (4.13) for the
PANSS Marder negative measures to 0.16 (2.23) for PANSS Marder uncontrolled hostility/excitement measures, again with LOCF analysis. Table 4 provides additional data on efficacy measures.

\section{Discussion}

\section{Summary of extant maintenance data}

Cumulatively, results from the previously discussed trials suggest that brexpiprazole is an effective maintenance agent for the treatment of schizophrenia, with a favorable tolerability profile that includes minimal akathisia and changes in lab values, including metabolic parameters and prolactin. ${ }^{16,17}$ Limitations to the long-term investigations include 1) the lack of an active comparator, 2) strict inclusion criteria that are not necessarily reflective of patients found in a clinical setting, and 3) concern that inclusion of patients from previous phase III clinical trials enriched the study population for those who tolerated brexpiprazole. These limitations make it difficult to predict brexpiprazole tolerability and efficacy in more diverse patient populations, such as in persons with schizophrenia who have multiple comorbidities. However, for providers who are considering brexpiprazole as maintenance therapy for an adult patient with schizophrenia, the available results suggest that if their patient tolerates brexpiprazole in the short term, they are likely to tolerate it in the long term.

\section{Brexpiprazole vs aripiprazole}

At this time, there has been one open-label trial comparing brexpiprazole $3 \mathrm{mg}$ daily to aripiprazole $15 \mathrm{mg}$ daily for the acute (6-week) treatment of schizophrenia. ${ }^{18}$ Participants were enrolled in this study if they were having an acute relapse of schizophrenia, and were then randomized 2:1 to brexpiprazole or aripiprazole. This resulted in 64 participants receiving brexpiprazole and 33 receiving aripiprazole. The average age of the patients was approximately 42 years, roughly $30 \%$ were female, average BMI was about 30 , and the majority were black or African-American (73\% aripiprazole group and $75 \%$ brexpiprazole group). In brief, results from this trial demonstrated comparable efficacy, as measured by similar reductions in PANSS scores from baseline to week 6 , similar rates of weight gain, but lower rates of akathisia in the brexpiprazole group (9.4\%) vs the aripiprazole group (21.2\%). Longer-term trial data would be helpful in discerning if these differences persist.

\section{Activating vs sedating adverse events}

An analysis of product labels and acute placebo-controlled study results for second-generation antipsychotics 
(aripiprazole, asenapine, brexpiprazole, cariprazine, iloperidone, lurasidone, olanzapine, paliperidone, quetiapine, risperidone, and ziprasidone) provided additional detail on activating and sedating side-effect rates. In this analysis, AEs were classified as activating (akathisia, restlessness, agitation, anxiety, and insomnia) or sedating (sedation, somnolence, and fatigue). The antipsychotics were compared by calculating attributable risk increase and number need to harm for each AE. Ultimately, brexpiprazole and paliperidone were the only two agents that were neither activating nor sedating in patients being treated for acute schizophrenia. ${ }^{19}$ Although these effects were examined in acutely ill persons with schizophrenia, the potential for persistence of these effects is a consideration when contemplating longer-term use.

\section{Weight changes}

With respect to weight gain, clinically significant weight increase ( $\geq 7 \%$ body weight) was higher in the 52 -week open-label safety studies than in the placebo-controlled acute efficacy studies. Rates were highest in the study conducted by Ishigooka et al: $24.2 \%$ for those who were analyzed in the safety data set. ${ }^{9}$ This is not necessarily surprising, as this population had the lowest average BMI (23.7) at baseline by at least 4 points, and lower BMI has been associated with higher risk of weight gain due to antipsychotics in metaanalyse ${ }^{20}$ and pooled analyses of brexpiprazole clinical studies. ${ }^{21}$ To put brexpiprazole-associated weight gain in the context of a comparator second-generation antipsychotic, Weiss et al analyzed weight-gain reports in acute and 52-week studies for brexpiprazole and aripiprazole. ${ }^{22}$ They found that by week 52, average weight gain associated with brexpiprazole was $3.2 \mathrm{~kg}$ vs $4.0 \mathrm{~kg}$ with aripiprazole, and weight increase $\geq 7 \%$ was $18.6 \%$ for brexpiprazole vs $25.3 \%$ for aripiprazole. These results suggest that weight gain appears to be similar for aripiprazole and brexpiprazole in the short and long term. An additional meta-analysis compared brexpiprazole and lurasidone efficacy and safety using data from acute studies. ${ }^{23}$ Results from this analysis suggest comparable efficacy between the two agents, but less average weight gain $(-0.69 \mathrm{~kg}, 95 \% \mathrm{CI}-1.22$ to -0.15 in favor of lurasidone) and more favorable outcomes with respect to changes in total cholesterol and low-density-lipoprotein cholesterol for lurasidone. When looking at the available data from a long-term, open-label, lurasidone-safety study, average weight gain was relatively low at 12 months $(0.7 \mathrm{~kg}$, 77 observed cases), and clinically significant weight gain occurred in $14.1 \%$ of observed cases. ${ }^{24}$

\section{Cost considerations}

Aigbogun et al addressed costs related to selecting between branded drug products. ${ }^{25}$ They compared brexpiprazole to lurasidone and cariprazine (as second-generation branded antipsychotics) and cost outcomes related to care for treating relapse of schizophrenia symptoms. They used data from the brexpiprazole relapse-prevention study ${ }^{8}$ and two similarly designed trials utilizing cariparazine ${ }^{26}$ and lurasidone. ${ }^{27}$ Primary outcomes were cost per relapse avoided and hospitalization avoided. Among the assumptions used to complete this study, the authors calculated that roughly $77 \%$ of relapse events were treated on an inpatient basis, and the payment structure modeled the US payer system. Results from this analysis identified brexpiprazole as superior to lurasidone and cariprazine on primary outcomes, translating into schizophrenia-related costs per year per patient of US\$20,150 (brexpiprazole), $\$ 22,510$ (cariprazine), and lurasidone $(\$ 25,510)$. The analysis was limited by the available randomized withdrawal studies used to model relapse, and in particular the dosing of lurasidone was likely suboptimal. An interpretation of these data could suggest that when considering between these options, absolute cost differences are not overly large, and other patientspecific factors and side-effect concerns may take precedence in the prescribing-decision process.

\section{Titration considerations}

In a post hoc analysis of the brexpiprazole randomized withdrawal trial, patient outcomes based on variable cross-titration schedules over the conversion phase were compared. ${ }^{28}$ Essentially, no outcomes or baseline variables were notably different between groups, aside from the observation that more gradual cross-titration (over 22-33 days) may improve tolerability, as noted by the lowest rates of TEAEs occurring when conversion was slowest.

\section{Conclusion}

Ultimately, results from the long-term brexpiprazole clinical trials and additional descriptive analyses demonstrate that brexpiprazole is efficacious as a maintenance agent for the treatment of schizophrenia, with a relatively well-tolerated AE profile. Specifically, there appear to be minimal activating and sedating side effects, and when compared to other second-generation antipsychotics, data thus far suggest that brexpiprazole has a propensity toward weight gain that is similar to aripiprazole, but potentially higher than lurasidone. These data suggest that brexpiprazole may be particularly appealing for adults sensitive to activating AEs who have previously not tolerated aripiprazole as an otherwise comparable generic alternative. 
At this time, there are very few safety data in patients with schizophrenia $>65$ years old, although this population has been studied in a 26-week open-label safety trial for adjunctive brexpiprazole use in the treatment of depression; ${ }^{29}$ in this analysis, no new concerns were identified, but the average dose was $1.8 \mathrm{mg}$, so it may not be appropriate to extrapolate these results to elderly patients with schizophrenia.

There are acute and long-term trials of brexpiprazole for the treatment of adolescents with schizophrenia that are ongoing and expected to provide useful efficacy and safety data for the use of brexpiprazole in this population.

Limitations on use of brexpiprazole that will need to be weighed by providers and patients include that the product is not available generically (and thus more costly than unbranded antipsychotics), there are limited data comparing brexpiprazole directly to other antipsychotics or in patients with comorbid psychiatric disease and/or medication use, and that tablets are the only available dosage form at this time.

\section{Acknowledgments}

The authors would like to thank Carol Shannon, an information specialist from the Taubman Health Sciences Library at the University of Michigan, for her assistance with the literature search for this review.

\section{Disclosure}

No external funding or writing assistance from any source was used in the creation of this review. The manufacturer (Otsuka/ Lundbeck) had no involvement in terms of funding or review of this manuscript. KW has no disclosures to report. In the past 12 months, LC has acted as a consultant for Acadia, Alkermes, Allergan, Intra-Cellular Therapies, Janssen, Lundbeck, Merck, Neurocrine, Noven, Otsuka, Pfizer, Shire, Sunovion, Takeda, Teva, and Vanda; as a speaker for Acadia, Alkermes, Allergan, Janssen, Lundbeck, Merck, Neurocrine, Otsuka, Pfizer, Shire, Sunovion, Takeda, and Teva; and has received royalties from Wiley (editor-in-chief, International Journal of Clinical Practice), UpToDate (reviewer), and Springer Healthcare (book). LC holds stocks (small number of shares of common stock) in Bristol-Myers Squibb, Eli Lilly, Johnson \& Johnson, Merck, and Pfizer (purchased more than 10 years ago). The authors report no other conflicts of interest in this work.

\section{References}

1. Citrome L, Stensbøl TB, Maeda K. The preclinical profile of brexpiprazole: what is its clinical relevance for the treatment of psychiatric disorders? Expert Rev Neurother. 2015;15(10):1219-1229.

2. Citrome L. The ABC's of dopamine receptor partial agonists-aripiprazole, brexpiprazole and cariprazine: the 15-min challenge to sort these agents out. Int J Clin Pract. 2015;69(11):1211-1220.
3. Otsuka. REXULTI (brexpiprazole) tablets, for oral use; 2018. Available from: https://www.otsuka-us.com/media/static/Rexulti-PI.pdf. Accessed December 26, 2018.

4. Kane JM, Skuban A, Ouyang J, et al. A multicenter, randomized, double-blind, controlled phase 3 trial of fixed-dose brexpiprazole for the treatment of adults with acute schizophrenia. Schizophr Res. 2015; 164(1-3):127-135

5. Correll CU, Skuban A, Ouyang J, et al. Efficacy and Safety of Brexpiprazole for the Treatment of Acute Schizophrenia: A 6-Week Randomized, Double-Blind, Placebo-Controlled Trial. Am J Psychiatry. 2015; 172(9):870-880.

6. Thase ME, Youakim JM, Skuban A, et al. Efficacy and safety of adjunctive brexpiprazole $2 \mathrm{Mg}$ in major depressive disorder: a phase 3, randomized, placebo-controlled study in patients with inadequate response to antidepressants. J Clin Psychiatry. 2015;76(9):1224-1231.

7. Thase ME, Youakim JM, Skuban A, et al. Adjunctive brexpiprazole 1 and $3 \mathrm{mg}$ for patients with major depressive disorder following inadequate response to antidepressants: a phase 3, randomized, double-blind study. J Clin Psychiatry. 2015;76(9):1232-1240.

8. Fleischhacker, WW, Hobart M, Ouyang J, et al. Efficacy and safety of brexpiprazole (OPC-34712) as maintenance treatment in adults with schizophrenia: a randomized, double-blind, placebo-controlled study. Int J Neuropsychopharmacol. 2017;20(1):11-21.

9. Ishigooka J, Iwashita S, Tadori Y. Long-term safety and effectiveness of brexpiprazole in Japanese patients with schizophrenia: a 52-week, open-label study. Psychiatry Clin Neurosci. 2018;72(6):445-453.

10. Forbes A, Hobart M, Ouyang J, Shi L, Pfister S, Hakala M. A LongTerm, Open-Label Study to Evaluate the Safety and Tolerability of Brexpiprazole as Maintenance Treatment in Adults with Schizophrenia. Int J Neuropsychopharmacol. 2018;21(5):433-441.

11. Maeda K, Sugino H, Akazawa H, et al. Brexpiprazole I: in vitro and in vivo characterization of a novel serotonin-dopamine activity modulator. J Pharmacol Exp Ther. 2014;350(3):589-604.

12. Frankel JS, Schwartz TL. Brexpiprazole and cariprazine: distinguishing two new atypical antipsychotics from the original dopamine stabilizer aripiprazole. Ther Adv Psychopharmacol. 2017;7(1):29-41.

13. American Psychiatric Association. Diagnostic and Statistical Manual of Mental Disorders: DSM-IV-TR. DSM-IV-TR. Washington, DC: American Psychiatric Association; 2000.

14. Citrome L. Brexpiprazole for schizophrenia and as adjunct for major depressive disorder: a systematic review of the efficacy and safety profile for this newly approved antipsychotic - what is the number needed to treat, number needed to harm and likelihood to be helped or harmed? Int J Clin Pract. 2015;69(9):978-997.

15. Ishigooka J, Iwashita S, Tadori Y. Efficacy and safety of brexpiprazole for the treatment of acute schizophrenia in Japan: a 6-week, randomized, double-blind, placebo-controlled study. Psychiatry Clin Neurosci. 2018;72(9):692-700.

16. Ivkovic J, Lindsten A, George V, Eriksson H, Hobart M. Effect of brexpiprazole on prolactin: an analysis of short- and long-term trials in schizophrenia. Eur Neuropsychopharmacol. 2017;27:S957-S958.

17. Eriksson H, Weiss C, Hobart M, Ouyang J, Weiller E. Effect of brexpiprazole on weight and metabolic parameters: an analysis of short-and long-term trials in schizophrenia. CNS Spectr. 2017;22(1):64.

18. Citrome L, Ota A, Nagamizu K, Perry P, Weiller E, Baker RA. The effect of brexpiprazole (OPC-34712) and aripiprazole in adult patients with acute schizophrenia. Int Clin Psychopharmacol. 2016;31(4):192-201.

19. Citrome L. Activating and sedating adverse effects of second-generation antipsychotics in the treatment of schizophrenia and major depressive disorder: absolute risk increase and number needed to harm. J Clin Psychopharmacol. 2017;37(2):138-147.

20. Bak M, Fransen A, Janssen J, van Os J, Drukker M. Almost all antipsychotics result in weight gain: a meta-analysis. PLoS One. 2014; 9(4):e94112.

21. Newcomer JW, Eriksson H, Zhang P, Weiller E, Weiss C. Changes in metabolic parameters and body weight in brexpiprazole-treated patients with acute schizophrenia: pooled analyses of phase 3 clinical studies. Curr Med Res Opin. 2018;34(12):2197-2205. 
22. Weiss C, Weiller E, Baker RA, et al. The effects of brexpiprazole and aripiprazole on body weight as monotherapy in patients with schizophrenia and as adjunctive treatment in patients with major depressive disorder: an analysis of short-term and long-term studies. Int Clin Psychopharmacol. 2018;33(5):255-260.

23. Ng-Mak D, Tongbram V, Ndirangu K, Rajagopalan K, Loebel A. Efficacy and metabolic effects of lurasidone versus brexpiprazole in schizophrenia: a network meta-analysis. Journal of Comparative Effectiveness Research. Epub Apr 26, 2018.

24. Correll CU, Cucchiaro J, Silva R, Hsu J, Pikalov A, Loebel A. Long-term safety and effectiveness of lurasidone in schizophrenia: a 22-month, open-label extension study. CNS Spectr. 2016;21(5):393-402.

25. Aigbogun MS, Liu S, Kamat SA, Sapin C, Duhig AM, Citrome L. Relapse prevention: a cost-effectiveness analysis of brexpiprazole treatment in adult patients with schizophrenia in the USA. Clinicoecon Outcomes Res. 2018;10:443-456.
26. Durgam S, Earley W, Li R, et al. Long-term cariprazine treatment for the prevention of relapse in patients with schizophrenia: a randomized, doubleblind, placebo-controlled trial. Schizophr Res. 2016;176(2-3):264-271.

27. Tandon R, Cucchiaro J, Phillips D, et al. A double-blind, placebocontrolled, randomized withdrawal study of lurasidone for the maintenance of efficacy in patients with schizophrenia. J Psychopharmacol. 2016;30(1):69-77.

28. Correll CU, Shi L, Weiss C, et al. Successful switching of patients with acute schizophrenia from another antipsychotic to brexpiprazole: comparison of clinicians' choice of cross-titration schedules in a post hoc analysis of a randomized, double-blind, maintenance treatment study. CNS Spectrums. Epub Oct 11, 2018.

29. Lepola U, Hefting N, Zhang D, Hobart M. Adjunctive brexpiprazole for elderly patients with major depressive disorder: an open-label, long-term safety and tolerability study. Int J Geriatr Psychiatry. 2018;33(10): $1403-1410$.
Neuropsychiatric Disease and Treatment

\section{Publish your work in this journal}

Neuropsychiatric Disease and Treatment is an international, peerreviewed journal of clinical therapeutics and pharmacology focusing on concise rapid reporting of clinical or pre-clinical studies on a range of neuropsychiatric and neurological disorders. This journal is indexed on PubMed Central, the 'PsycINFO' database and CAS,

\section{Dovepress}

and is the official journal of The International Neuropsychiatric Association (INA). The manuscript management system is completely online and includes a very quick and fair peer-review system, which is all easy to use. Visit http://www.dovepress.com/testimonials.php to read real quotes from published authors.

Submit your manuscript here: http://www.dovepress.com/neuropsychiatric-disease-and-treatment-journal 